\title{
Comparing Early Pragmatics in Typically Developing Children and Children with Neurodevelopmental Disorders
}

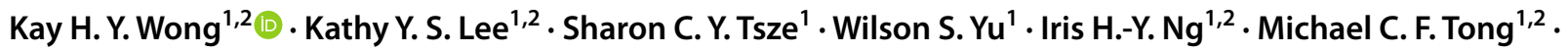 \\ Thomas Law ${ }^{1,2}$
}

Accepted: 26 August 2021 / Published online: 4 September 2021

(C) The Author(s), under exclusive licence to Springer Science+Business Media, LLC, part of Springer Nature 2021

\begin{abstract}
This study examined the early pragmatic language skills in typically developing (TD) preschool-age children, children with language impairment (LI) and children with autism spectrum disorder (ASD). Two hundred and sixty-two TD children, 73 children with LI, and 16 children with ASD were compared on early pragmatics through direct assessment (DA). Post hoc analysis revealed that children in two clinical groups displayed significant pragmatic language deficits. Children in the ASD group who were older exhibited comparable degree of impairments as their LI peers, suggesting a relatively stagnant development of pragmatic language skills in children with ASD. Findings also supported the use of DA in identifying pragmatic language deficits, which have implications for the adoption of this assessment approach in clinical settings.
\end{abstract}

Keywords Early pragmatics $\cdot$ Language impairment $\cdot$ Autism spectrum disorder $\cdot$ Direct assessment

\section{Introduction}

Pragmatics refers to the use of language in social situations and is considered to be one of the essential elements of human communication, in addition to the knowledge of form and content (Bates, 1976). According to Landa (2005), pragmatics can be categorized into three major domains. The first domain is communicative intentions, which refers to the different acts expressed by a communicator and through which specific communicative goals are achieved. The second domain is presupposition, which relates to the capability of establishing assumptions between communicative partners for the provision of appropriate information in a context. The last domain is discourse management, which involves the employment of communication strategies such as topic maintenance, initiation, and termination. As early as in the first year of life, infants start to engage in triadic

Kay H. Y. Wong

kaywong@ent.cuhk.edu.hk

1 Department of Otorhinolaryngology, Head \& Neck Surgery, The Chinese University of Hong Kong, Shatin, New Territories, Hong Kong SAR, China

2 Institute of Human Communicative Research, The Chinese University of Hong Kong, Shatin, New Territories, Hong Kong SAR, China joint attention to external entities (Stephens \& Matthews, 2014). They also can determine the meaning of pointing gestures based on shared experience with adults (Bohn et al., 2018) as well as using gestures to influence others' mental states (Tomasello et al., 2007). They then continue to acquire other fundamental pragmatic language skills such as ability to perform appropriate turn-taking and response to repairs in conversations (see Adams, 2002, for summary).

It is universally acknowledged that social communication difficulties are prevalent among children with autism spectrum disorder (ASD). Pragmatic language deficits have been found in school-age children with language impairment (LI), despite the traditional belief that they have relative strengths in the use of language as compared to their structural language skills (Davies et al., 2016). This has called for a careful investigation of pragmatic functioning of children who do not meet the clinical diagnostic criteria of ASD but have received the diagnosis of neurodevelopmental disorders. To date, the comparisons of pragmatic language skills between populations of different neurodevelopmental disorders, particularly in preschool-age children, remain largely unexamined. In this study, we aim to fill this gap by providing an account of the manifestations of typical and atypical pragmatic language skills in young children. 


\section{Pragmatic Language Deficits in ASD}

Persistent deficits in social communication and interaction are symptoms shared by individuals with ASD (American Psychiatric and Association, 2013). Impairments in nonverbal communicative behaviors are among the early indicators of ASD (Hyman et al., 2020). Significant early impairment of joint attention is a distinctive feature that distinguishes preschool-age children with ASD from their typically developing (TD) peers (Kasari et al., 2012; Lawton \& Kasari, 2012; Mundy, 2016). Another important indicator of early pragmatic impairment in this population is reduced (Choi et al., 2020; West et al., 2020) and atypical use of gestures (Manwaring et al., 2018). Other domains of pragmatic language deficits include reduced variety and frequency of communicative acts (Delehanty \& Wetherby, 2021), diminished awareness of their own and others' intentions (Williams \& Happé, 2010), impaired turn-taking skills (Schertz et al., 2018), and inability to initiate or respond to request for clarification to repair conversational breakdowns (Martin et al., 2017). Taken together, pragmatic language deficits are manifested behaviorally in a variety of domains which comprise the central components that characterize ASD.

\section{Pragmatic Language Deficits in LI}

Pragmatic language deficits have also been found in children with LI (Gibson et al., 2013; Osman et al., 2011). Preschool-age children who had language delay displayed poorer pragmatic language skills as compared to their TD peers (O'Neill, 2007). During parent-child interactions, preschool-age children with LI were less able to select and match suitable linguistic forms to the appropriate communicative functions (van Balkom \& Verhoeven, 2004). They were also not equipped with the linguistic capacities to sustain a coherent and fluent discourse. In addition, diminished use of deictic and conventional gestures has been documented in children with LI (Lüke et al., 2017; Manwaring et al., 2019). The deficits lied not only in the production but in the comprehension of gestures integrated with speech (Botting et al., 2010; Wray et al., 2016). In short, apart from syntax and semantics, pragmatics is one of the areas of impairment in children with LI.

\section{Pragmatic Language Deficits in ASD and LI}

Traditionally, LI and ASD are considered as two distinct clinical conditions. The conceptualization of the potential underlying overlapping etiology has been discussed, given an above chance level comorbidity (Bartlett et al., 2012; Bishop, 2010; Tomblin, 2011) and similar language profiles (Boucher, 2012; Norbury et al., 2014). Turning to pragmatic language difficulties, the extent and nature of impairment are suggested to be different in these two clinical groups. Based on results from the Children's Communication Checklist-2 (CCC-2; Bishop, 2003), Norbury et al. (2004) found that school-age children with ASD had a more profound degree of pragmatic language deficits as compared to those with LI. Andrés-Roqueta and Katsos (2020) investigated whether structural language and Theory of Mind (ToM) skills predicted success in pragmatic language skills in school-age children. Their findings supported that children in both clinical groups faced challenges in linguistic pragmatics tasks requiring their knowledge of linguistics and pragmatic maxims. They had difficulties in identifying a sentence of a speaker saying that "some of the toys are inside the boxes" as being under-informative given a picture in which all of the toys are inside the boxes. However, children with ASD faced exceptional difficulties with social pragmatics task (e.g., identifying hidden intentions of others) as predicted by their poorer ToM competence.

\section{Approaches to Assessment of Pragmatic Language Skills}

The assessment of pragmatic language skills using appropriate approaches is crucial to children with difficulties in social communication (Farmer \& Oliver, 2005). The assessment methods can be categorized into checklists, observational protocols, standardized pragmatic language tests, and assessment of comprehension of pragmatic language (Adams, 2002). The first two methods are observational assessments (OAs) in which children's pragmatic behaviors are observed in natural contexts such as during parent-child interactions. For instance, the Language Use Inventory (LUI; O’Neill, 2007) and CCC-2 (Bishop, 2003) are commonly used parental checklists of pragmatic language skills. Examples of observational protocols with published psychometric properties include the Pragmatic Protocol (Prutting \& Kittchner, 1987) and the Pragmatic Observational Measure (Cordier et al., 2014). The latter two methods are direct assessments (DAs) in which children are directly tested with questions and/or clinical tasks designed to probe or elicit different pragmatic language skills. Children are assessed in an isolated and one-to-one test environment and are asked to produce responses for characters in social situations depicted in pictures or to make judgements about the efficacy of verbal messages. Standardized pragmatic language tests and procedures such as the Test of Pragmatic Language-Second Edition (TOPL-2; Phelps-Terasaki \& Phelps-Gunn, 2007) and the Implicature Comprehension Test (ICT; Wilson 
\& Bishop, 2019) are used for both research and clinical purposes.

Traditionally, OA is preferred as pragmatic language skills are contextually dependent by its nature. However, potential limitations of OA are acknowledged. Checklists though allow investigators to obtain information quickly, they are subject to informant manipulation. In addition, pragmatic assessments that involve observations of structured interactions are often time consuming and difficult to be applied in a clinical context (Toe et al., 2020). Hence, DA is increasingly being adopted to achieve efficient evaluation of children's pragmatic language skills. Sturrock et al. (2020) compared the use of OA and DA of structural and pragmatic language skills for school-age children with ASD. Results supported the complementary use of both measures to obtain a holistic view of pragmatic language skills in children.

In summary, the precise extent and nature of pragmatic language impairment in these two clinical populations are largely unknown and worth investigating. The feasibility of using DA of pragmatic language abilities in young children should also be explored.

\section{The Present Study}

The present study seeks to address the following research gaps. To date, most studies in early pragmatic language development concerned only the typical developmental trajectory in preschool-age children (Julien et al., 2019; Longobardi et al., 2017). Investigations of atypical pragmatic language development merely compared the TD group with only one clinical group such as ASD. There were few studies such as Geurts and Embrechts (2008) that have examined pragmatic language deficits among preschool-age children from different clinical groups. Comparisons were usually made among groups of school-age children (Andrés-Roqueta $\&$ Katsos, 2020; Ferrara et al., 2020), groups of children with a broad age range (Charman et al., 2003; Luyster et al., 2007), or groups of children consisting of highly heterogeneous background such as developmental delay (Weismer et al., 2010). Cross-population investigation of pragmatic language skills in preschool-age children is scarce and therefore warranted.

Furthermore, most of the studies have investigated specific pragmatic language skills. Exploring whether deficits are present in the domains of communicative intentions, presupposition, and discourse management will further our understanding of early pragmatic language profiles in different clinical populations. For our present study, the assessment of the presence of eye contact, overall communicative intention, response to name, and comprehension of conventional gestures were categorized as communicative intentions skills. The assessments of understanding the intentions and emotion of others were categorized as presupposition skills. Finally, the assessment of topic maintenance skills, appropriate response in conversational context, and response to conversational repair request were categorized as discourse management skills.

As mentioned above, many of the previous studies used OAs to examine specific pragmatic language skill during parent-child interactions (Landa, 2005). In contrast, a novelty in this study is to measure early pragmatic language skills in preschool-age children through DA. Therefore, the current study aims to examine and compare the early pragmatic language skills among TD preschool-age children, children with LI, and children with ASD. The specific research questions are as follows:

1. Is there a significant difference in the early pragmatic language skills in TD preschool-age children, children with LI, and children with ASD?

2. Are there significant differences in the pragmatics subdomains of communicative intentions, presupposition, and discourse management in the three groups?

3. Can early pragmatic language skills be measured by DA?

For the first research question, our central hypothesis is that children in the two clinical groups (LI and ASD) would have deficits in pragmatic language skills in comparison to the TD control group. Children with ASD would display a greater degree of deficits than those with LI. For the second research question, it is hypothesized that deficits would be found in children in the clinical groups across all three domains as compared to their TD peers. For the third research question, it is expected that DA can capture early pragmatic skills development based on findings reported in Sturrock et al. (2020).

\section{Methods}

\section{Participants}

Three groups of Cantonese-speaking preschool-age children participated in this study. The participants in the TD group and the LI group were drawn from a large-scale test validation study of a language assessment instrument known as the Hong Kong Cantonese Language Assessment for Preschool children (HK-CLASS-P) in Hong Kong. The participants in this test validation study were between $2 ; 0$ and $3 ; 11$. They were recruited through a two-stage cluster sampling procedure from local schools in three geographical regions in Hong Kong, including the Hong Kong Island, Kowloon, and New Territories. 
Children who were aged between 2;0 and 2;11 and did not attend local schools were also recruited through the social media platforms and university internal mass mail system. An electronic promotional advertisement was sent to all undergraduates, postgraduates, staff members of the Chinese University of Hong Kong (CUHK) via the internal weekly mass mail system. The same advertisement was posted on our division of speech therapy's Facebook. The advertisement contains a registration link through which parents can sign up for the study. Upon receiving their registrations, our research staff in the team will contact the parents via phone and/or email to schedule for testing.

As part of the inclusion criteria in the original test validation study, children in both the TD and LI groups were all using Cantonese as the first and dominant language, had no significant hearing impairment, and no known or reported history of ASD, psychiatric disorders, and intellectual disability. Their normal hearing status were confirmed by a pure-tone air conduction hearing screening with a threshold of $25 \mathrm{~dB}$ HL. Children meeting one of the following two criteria were included in the LI group: (1) being diagnosed by a qualified speech-language pathologist based on informal assessment at the time of testing; (2) having failed the Cantonese Receptive Vocabulary Test (Lee et al., 1996), a standardized test assessing the receptive vocabulary of Cantonese-speaking children in Hong Kong. This test was used as it was the only standardized language assessment tool for Cantonese-speaking preschool-age children in Hong Kong when the study was conducted. For the first criteria, a speech-language pathologist made the diagnostic decision based on participants' performances in receptive vocabulary, receptive grammar, expressive vocabulary, expressive grammar, and pragmatics using an array of tasks including picture-pointing, object manipulation, picture naming, picture description, and narrative production. For the second criteria, children whose receptive vocabulary scores fell below one standard deviation of the mean were considered to have failed the test. For the present study, we included all participants in the TD and the LI groups in the original test validation study.
Participants in the ASD group were recruited through the social media platform and university internal mass mail system with the same procedure described above. Children were enrolled into the study if they had a confirmed diagnosis of ASD or showed symptoms of restrictive and repetitive behaviors and social communication difficulties as reported by their caregivers. Their ASD status and severity level were ascertained through a standardized screening procedure using the Childhood Autism Rating Scale-Second Edition (CARS-2; Schopler et al., 2010). The CARS-2 contains 15 items rated on a 4-point Likert scale. Based on the total score, individuals are classified into one of the three severity groups, which are (1) No ASD, (2) Mild-to-Moderate ASD, and (3) Severe ASD. The CARS-2 was administered by a qualified speech-language pathologist. Ratings were assigned based on both direct observations of the participants' behaviors during a thirty-minute parent-child interaction and information obtained from a one-hour interview of the caregiver.

The final sample consisted of 262 TD controls (128 males, 134 females), 73 LI children (41 males, 32 females), and 16 ASD children (15 males, 1 female; 5 mild to moderate ASD, 11 severe ASD). Demographic data (chronological age and gender) of all participants are presented in Table 1. Differences in chronological age were not statistically significant between the TD vs. LI groups nor the TD vs. ASD groups whereas the difference in chronological age was statistically significant between LI vs. ASD groups. For details of the comparisons in chronological age between groups, please refer to Table 1 .

\section{Procedure}

Ethical approval for this study was obtained from the Joint CUHK-New Territories East Cluster Clinical Research Ethics Committee. Informed consent was obtained from each child participant's parent or legal guardian included in this study.

In the original test validation study, children in the TD and LI groups were invited to participate in the testing at the

Table 1 Demographic information of participants in TD, LI, \& ASD groups

\begin{tabular}{|c|c|c|c|c|c|c|c|}
\hline \multirow[t]{2}{*}{ Characteristics } & \multicolumn{2}{|l|}{$\mathrm{TD}(n=262)$} & \multicolumn{2}{|l|}{$\mathrm{LI}(n=73)$} & \multicolumn{2}{|l|}{$\operatorname{ASD}(n=16)$} & \multirow[t]{2}{*}{ Post hoc comparisons } \\
\hline & $M(S D)$ & Range & $M(S D)$ & Range & $M(S D)$ & Range & \\
\hline Males: Females & $128: 134$ & N/A & $41: 32$ & N/A & $15: 1$ & N/A & N/A \\
\hline CA (months) & $35.27(6.761)$ & $24-47$ & $33.79(6.50)$ & $25-47$ & 41.25 (10.78) & $30-65$ & $\begin{array}{l}\mathrm{TD}=\mathrm{LI}, p=.225 \\
\mathrm{TD}=\mathrm{ASD}, p=.079 \\
\mathrm{ASD}>\mathrm{LI}, p=.01^{*}\end{array}$ \\
\hline
\end{tabular}

$T D$ Typically Developing, $L I$ Language Impairment, $A S D$ Autism Spectrum Disorder, N/A Not Applicable, $C A$ Chronological Age, $M$ Mean, $S D$ Standard Deviation. Post hoc pairwise comparisons were performed using Dunn's procedure (Dunn, 1964) with a Bonferroni correction for multiple comparisons. Statistically significant effect is indicated with $* p<.05$ 
audiology center at Prince of Wales Hospital, the teaching hospital of CUHK. The children received a hearing screening and were tested for their language abilities using the HK-CLASS-P in a quiet room individually by speech-language pathologists, audiologists, or trained research assistants in the research team. All test administrators performed onsite scoring of the children's responses. The test consisted of items that assess structural and pragmatic language skills. For the structural language skills, children were required to respond either by choosing a picture displayed on the screen or by verbal output. For pragmatic language skills, children were rated for observations on general social communication skills and verbal or non-verbal responses to test items on the Pragmatic Language Skills Subscale. For the present study, the relevant data pertaining to the pragmatic language skills were extracted from the datasets for between-group comparisons.

The testing on ASD group was conducted between April and July 2020. In view of the COVID-19 pandemic situation and the CUHK's policy of temporary suspension of inperson teaching and research activities, the data collection was conducted online. Participants were tested via Zoom, an online meeting software. The participants were accompanied by their caregivers to the online testing. All participants in the ASD group accessed the test via a personal computer or tablet with uninterrupted internet connection. They completed the test with no difficulties regardless of the device used. The test administrator was a graduate student of speech-language pathology. A one-hour interview with the caregivers using the Questionnaire for Parents or Caregivers (CARS2-QPC) was conducted for the purpose of obtaining information for CARS-2 ratings. To observe for the general social communication skills and ASD symptoms for CARS-2 ratings, caregivers and participants were then asked to engage in a thirty-minute parent-child interaction. In the final part of the testing, the test administrator displayed the stimuli of the Pragmatic Language Skills Subscale of the HK-CLASS-P using the share screen function in Zoom. Scoring of the children's responses were completed online by the same test administrator and according to the same procedure and criteria as in the testing of the TD and LI groups in the original test validation study. All testing sessions were recorded using the Zoom's in-built recording function. A qualified speech-language pathologist completed CARS-2 ratings offline by viewing the recordings of the 16 children with ASD included in this study.

\section{Measures}

The outcome measure is the total score of the Pragmatic Language Skills Subscale of the HK-CLASS-P. The HK-CLASS-P is a comprehensive language assessment currently in the process of production and publication. The test comprises Receptive Vocabulary, Expressive Vocabulary, Receptive Grammar, Expressive Grammar, and Pragmatic Language Skills Subscales. The Pragmatic Language Skills Subscale is the only available DA for Cantonese-speaking preschool-age children in Hong Kong. The inclusion of all test items in this test including those in the Pragmatic Language Skills Subscale was based on results of Rasch analyses (Rasch, 1960). Two fit statistics (i.e., infit and outfit statistics) were used as the indicators for the model fit in the Rasch analysis to determine the quality of items. We adopted a standardized value of 2.0 to indicate a data misfit (Cook et al., 2001). Only items with infit and outfit values that are below the criteria for data misfit were included. Fit statistics also revealed a reasonable distribution of item difficulty from 36.72 to 69.64 . Results suggested that the items are with high quality in measuring a child's language ability following the Rasch item response model. The spread of item difficulty indicates that the item pool covers relatively easy to highly difficult items to suit various abilities of children.

The reliability of the test is evaluated in terms of testretest, intra-rater, and inter-rater reliability by different models of intra-class correlation with coefficients ranged from 0.73 to 1.00 . Cronbach's alpha coefficients are all greater than 0.83 indicating satisfactory internal consistency. The validity is evaluated following the COnsensus-based Standards for the selection of health status Measurement INstruments (COSMIN) taxonomy of psychometric properties (Mokkink et al., 2010). The Rasch Factor Analysis results showed that $48 \%$ of total variance was explained by the Rasch measure, and the first residual component explained only $1.8 \%$ of total variance in an eigenvalue of 5.2. Correlation coefficients among all subscale scores and total scores are highly correlated (ranged from 0.87 to 0.96 ) in the positive direction. The test score is also shown to be able to discriminate children with LI from TD children.

For our present study, the Pragmatic Language Skills Subscale was used. The selected test items represent a wide range of early pragmatic language skills in the three pragmatic language domains proposed by Landa (2005). The testing methods follow the DA approach as described above. Participants' pragmatic language skills were directly elicited by questions. The following examples illustrate the elicitation procedures and scoring criteria. In the communicative intentions assessment, participants were required to comprehend gestures performed by the test administrator. They were asked to state the meaning of a "waving" and "thumbs up" gestures. Participants would be given a score if they indicated a conventional meaning of the gestures. In the presupposition assessment, participants were presented with pictures depicting different characters and objects in a context. They were asked to give a response to tell what the characters intend to do or how they feel about the situations. For instance, the test administrator displayed a picture 
stimulus depicting a mother holding a knife and an apple and asked: "What does mommy want to do?" The participants would obtain a score when a verbal or nonverbal response of cutting an apple was given. In the discourse management assessment, participants' abilities to maintain a conversation on the same topic was tested with a picture description task during which the test administrator elicited responses by asking different wh-questions consecutively. At least three conversational turns on the same topic are required to obtain a score for this test item. For a detailed description of all test items and the respective scoring criteria, please refer to Table 2 .

\section{Data Analysis}

Statistical analyses were conducted using IBM SPSS Statistics package for Windows (version 22). A $p$-value of 0.05 was selected as the criterion for determining statistical significance. The sample was divided into TD, LI, and ASD groups for comparisons. Our first analysis was to compare the overall pragmatic language skills across groups. The group membership was used as the independent variable. The total score of the Pragmatic Language Skills Subscale was used as the dependent variable. The pragmatic language skills scores were normally distributed for the ASD group but not the TD and LI groups, as assessed by Shapiro-Wilk's test $(p<0.05)$, which showed unequal variances across groups. Given the lack of normality of the data, Kruskal-Wallis $\mathrm{H}$ test, a nonparametric analysis, was employed to examine the main effects (Kruskal \& Wallis, 1952).

Our further analyses were to compare the performances in the three subdomains of pragmatic language skills (i.e. communicative intentions, presupposition, discourse management) across the three groups. The group membership remained as the independent variable while the summative scores of the test items in the respective subdomains were the dependent variables. Shapiro-Wilk's tests were performed for all subdomain measures. Similarly, all three subdomain scores were normally distributed for the ASD group but not the TD and LI groups $(p<0.05)$ which again showed unequal variances across groups. The Kruskal-Wallis $\mathrm{H}$ test was thus used (Kruskal \& Wallis, 1952). Post hoc pairwise comparisons using Dunn's procedure (Dunn, 1964) were performed for all analyses.

\section{Results}

Results for the overall pragmatic language skills scores indicated a statistically significant main effect between groups $\left(\chi^{2}(2)=45.409, p=0.000\right)$. Subsequently, pairwise comparisons were performed using Dunn's procedure (Dunn,
1964) with a Bonferroni correction for multiple comparisons. Table 3 and Fig. 1 present the overall pragmatic language skills scores across groups. Adjusted $p$-values are presented. This post hoc analysis revealed statistically significant differences in pragmatic language skills scores between the TD group (mean rank $=197.15$ ) and LI group (mean rank $=115.25$ ) with $p=0.000$ and between the TD group and ASD group (mean rank $=106.81$ ) with $p=0.002$. In contrast, the LI group and ASD group did not differ in pragmatic language skills scores.

For further analyses on subdomains of pragmatic language skills, significant main effects between groups were found in communicative intentions $\left(\chi^{2}(2)=39.433, p=0.000\right)$, presupposition $\left(\chi^{2}(2)=28.920, p=0.000\right)$, and discourse management $\left(\chi^{2}(2)=43.004, p=0.000\right)$. Pairwise comparisons using Dunn's (1964) procedure with a Bonferroni correction were also performed for all subdomains. Between-group and post hoc pairwise comparisons on subdomain scores are presented in Table 3 and Figs. 2, 3 and 4. Post hoc analyses indicated statistically significant differences in communicative intentions between the TD group (mean rank $=194.94$ ) and LI group (mean rank $=127.67$ ) with $p=0.000$ and between the TD group and the ASD group (mean rank $=86.31$ ) with $p=0.000$ but not significant between the LI group and the ASD group; in presupposition between the TD group (mean rank = 191.52) and the LI group (mean rank =121.75) with $p=0.000$ but not significant in group comparisons involving the ASD group (mean rank $=169.41$ ); in discourse management between the TD group (mean rank $=195.16$ ) and the LI group (mean rank $=117.17$ ) with $p=0.000$ and between the TD group and the ASD group (mean rank $=130.59$ ) with $p=0.023$ but not significant between the LI group and the ASD group.

To conclude, significant differences in the overall pragmatic language skills scores were found between typically and atypically developing children but not between children with LI and children with ASD. The breakdown analyses on the subdomains reflected similar patterns observed in the overall pragmatic language skills except for presupposition, the performance of which was not significantly different between TD children and children with ASD. Our results also supported the use of DA in examining early pragmatic skills in preschool-age children.

\section{Discussion}

The present study aimed to evaluate the early pragmatic language skills in TD preschool-age children, children with LI, and children with ASD. Impairment in social communication is one of the defining characteristics of individuals with ASD. Pragmatic language deficits have also been identified in school-age children with LI. To the best of our knowledge, 


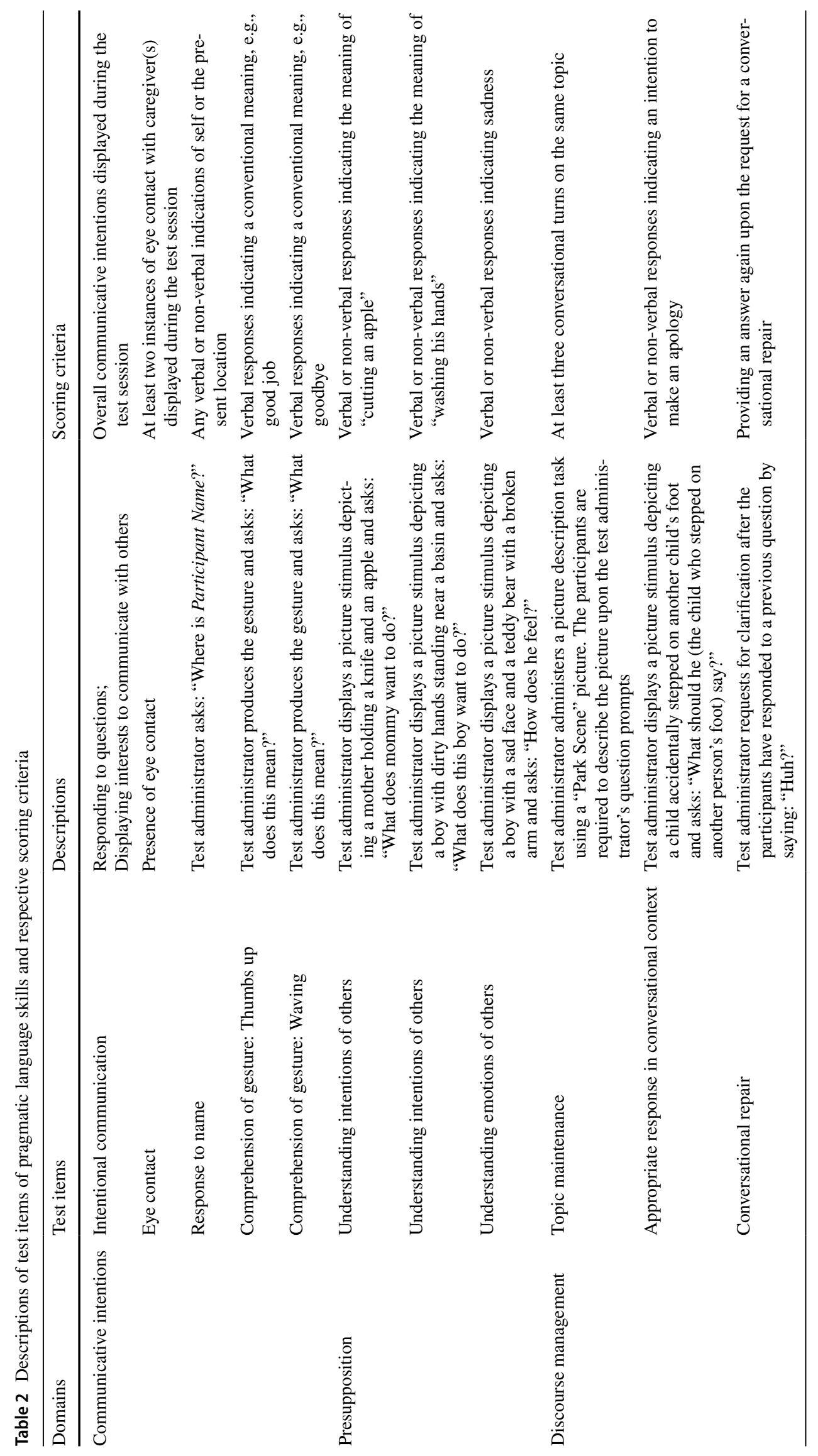


Table 3 Between-group and post hoc pairwise comparisons on pragmatic language skills, communicative intentions, presuppositions, and discourse management

\begin{tabular}{|c|c|c|c|c|c|c|c|}
\hline \multirow[t]{2}{*}{ Measures } & \multicolumn{2}{|l|}{$\mathrm{TD}(n=262)$} & \multicolumn{2}{|l|}{$\mathrm{LI}(n=73)$} & \multicolumn{2}{|l|}{$\operatorname{ASD}(n=16)$} & \multirow[t]{2}{*}{ Post hoc comparisons } \\
\hline & $M(S D)$ & Range & $M(S D)$ & Range & $M(S D)$ & Range & \\
\hline Pragmatic language skills & $8.06(2.922)$ & $0-12$ & $5.32(3.312)$ & $0-12$ & $5.13(2.964)$ & $0-9$ & $\begin{array}{l}\mathrm{TD}>\mathrm{LI}, p=.000 * * * \\
\mathrm{TD}>\mathrm{ASD}, p=.002 * * \\
\mathrm{LI}=\mathrm{ASD}, p=1\end{array}$ \\
\hline Communicative intentions & $4.02(1.467)$ & $0-6$ & $2.95(1.598)$ & $0-6$ & $2.06(1.569)$ & $0-4$ & $\begin{array}{l}\mathrm{TD}>\mathrm{LI}, p=.000 * * * \\
\mathrm{TD}>\mathrm{ASD}, p=.000^{* * *} \\
\mathrm{LI}=\mathrm{ASD}, p=.401\end{array}$ \\
\hline Presupposition & 1.68 (1.099) & $0-3$ & $0.88(1.040)$ & $0-3$ & $1.44(0.892)$ & $0-3$ & $\begin{array}{l}\mathrm{TD}>\mathrm{LI}, p=.000 * * * \\
\mathrm{TD}=\mathrm{ASD}, p=1 \\
\mathrm{LI}=\mathrm{ASD}, p=.236\end{array}$ \\
\hline Discourse management & $2.35(0.875)$ & $0-3$ & $1.49(1.082)$ & $0-3$ & $1.63(1.147)$ & $0-3$ & $\begin{array}{l}\text { TD }>\text { LI, } p=.000 * * * \\
\text { TD }>\text { ASD, } p=.023 * \\
\text { LI }=\text { ASD, } p=1\end{array}$ \\
\hline
\end{tabular}

$T D$ Typically Developing, $L I$ Language Impairment, $A S D$ Autism Spectrum Disorder, $M$ Mean, $S D$ Standard Deviation. Post hoc pairwise comparisons were performed using Dunn's procedure (Dunn, 1964) with a Bonferroni correction for multiple comparisons. Statistically significant effects are indicated with $* p<.05, * * p<.01, * * * p<.001$

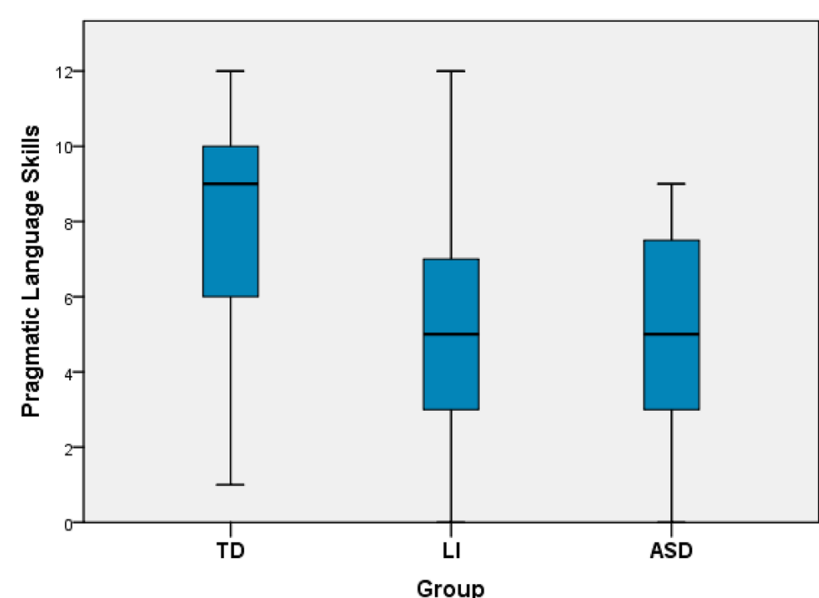

Fig. 1 Boxplot illustrating the distributions of the pragmatic language skills score in each group

this study is the first of its kind to compare a broad range of early pragmatic language skills in TD preschool-age children to those with neurodevelopmental disorders through DA. Key findings are explored below.

First, findings confirmed our hypothesis that preschoolage children with ASD would demonstrate poorer early pragmatic language skills compared to their TD peers. This finding is in accord with what has been reported in earlier studies. As indicated above, ASD is a neurodevelopmental disorder that appears in early childhood and is characterized by persistent deficits in social communication and interaction (American Psychiatric Association, 2013). Impairments have been identified in preschool-age children with ASD in different areas of pragmatic skills, including joint attention (Kasari et al., 2012), gestures (Choi et al., 2020; West et al.,

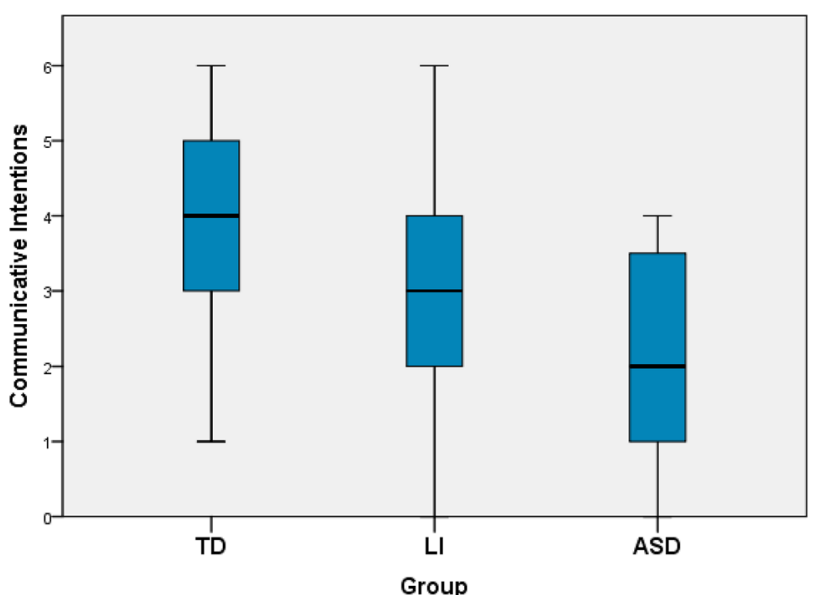

Fig. 2 Boxplot illustrating the distributions of the communicative intentions score in each group

2020), communicative acts (Delehanty \& Wetherby, 2021), turn-taking skills (Schertz et al., 2018), and conversational repairs (Martin et al., 2017). The test items employed in the current study were specifically designed to characterize the pragmatic language abilities holistically. Therefore, it was expected that children with ASD would demonstrate impairments across a range of social-pragmatic skills. The lower overall pragmatic language skills score in children with ASD as compared to that of TD peers further substantiates that social communication is a core area of challenge for children with ASD.

Second, the analyses on the subdomains of pragmatic language skills revealed that children with ASD were particularly poorer in the domains of communicative intentions and discourse management. However, our results did not 


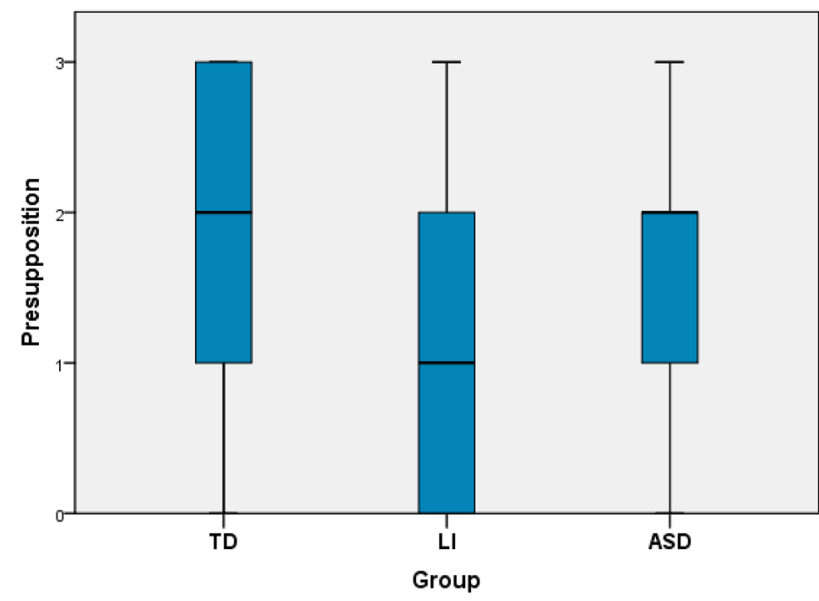

Fig. 3 Boxplot illustrating the distributions of the presupposition score in each group

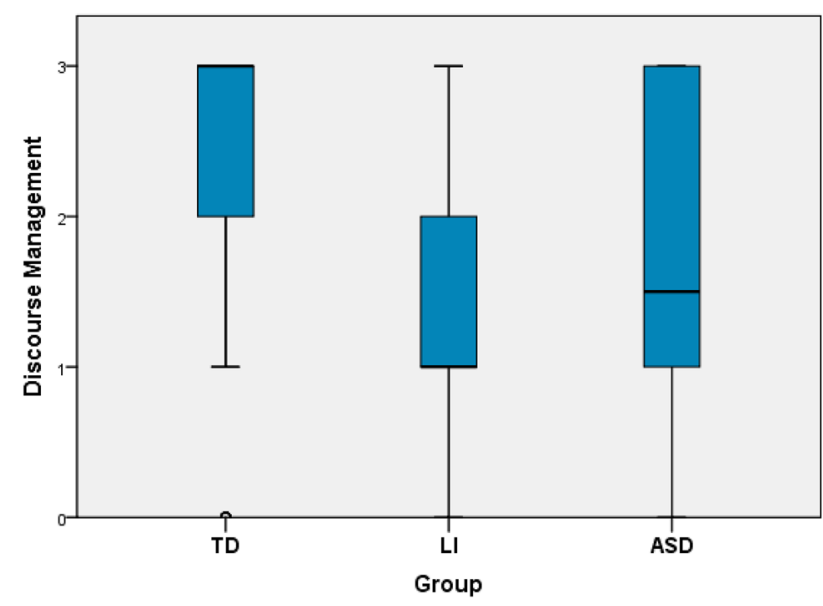

Fig. 4 Boxplot illustrating the distributions of the discourse management score in each group

find a significant difference in the domain of presupposition between TD children and children with ASD. For this subdomain, we investigated the abilities of preschool-age children in comprehending the mental states of others, such as intention understanding and emotion recognition, which are fundamental to presuppositional competence and communicative interactions (Hamilton, 2009). Though it has been suggested that young children with ASD have a diminished awareness of their own and others' intentions (Williams \& Happé, 2010), the deficits lied in the understanding of intentions involving social sharing and that the understanding of others' intentional acts were generally intact in young children with ASD (Broekhof et al., 2015). Our findings echoed that of the previous studies that young children with ASD can understand other people's simple intentional acts to the same extent as their TD peers. They were equally able to predict the intended actions of the persons about to perform a routine task (i.e., cutting an apple with a knife, washing one's dirty hands). The other indicator of mental states included in this subdomain was emotion recognition. Children with ASD have been found to have lower abilities in emotion recognition than their TD peers (see Harms et al., 2010, for review). However, this is not shown in the present study as children in the ASD group were as competent as the children in the TD group in indicating the emotional state of the person. Because of the centrality in emotional expression, the majority of emotion recognition research predominately focused on facial expressions of human faces (Song \& Hakoda, 2018). In our study, we presented a picture of a character in a scenario which has been found to facilitate emotion recognition by children with ASD (Brosnan et al., 2015). The contextual information and the verbal content of the prompting question may also have provided cues for them to recognize the basic emotion (i.e., sadness) expressed in our picture stimuli.

The third main finding is that preschool-age children with LI also face challenges in the use of language, which is in line with previous finding that the overall pragmatic language skills in children aged 18-47 months was significantly poorer than that in TD children (O'Neill, 2007). This result challenges the notion that children with LI have a mild degree of deficits in pragmatic language abilities relative to their structural language abilities (Davies et al., 2016). A study conducted by Tomblin et al. (2004) revealed that approximately $60 \%$ of children with LI have semantic and syntactic skills that were average compared to their TD peers, but slightly above average pragmatic language skills. While it is possible to have relative strength in pragmatics against a relative weakness in structural language in children with LI, it has been hypothesized that pragmatic language deficits can be the consequence of structural language impairment (Ketelaars \& Embrechts, 2017). The main argument is that pragmatic competence is dependent on both receptive and expressive language skills. In the present study, the performance exhibited by children with LI may also be susceptible to their receptive and expressive language deficits. One example is the test item assessing topic maintenance skills. The participants were rated on their ability to keep to a single topic for multiple turns in a picture description task. The performance in this task was contingent upon the participants' abilities to comprehend the questions and to describe the picture. The inherent demands on structural language abilities may have inadvertently affected their performance. Though it is not within the scope of the present study to evaluate the relationship between structural language abilities and pragmatic language abilities in children, past research has indicated that they are highly correlated (Matthews et al., 2018). Using confirmatory factor analysis (CFA), Wilson and Bishop (2021) found that pragmatic and structural language impairments often co-occur in 
school-age children. Their findings supported the view that there is a reciprocal and bidirectional relationship between the development of structural language skills and pragmatic language skills. In this regard, further investigation is warranted to verify whether structural language abilities are factors that influence pragmatic language skills development and vice versa in preschool-age children with LI.

Our findings also suggested that there is no significant difference in pragmatic language deficits between preschoolage children with LI and ASD. However, it is important to note that there was a significant difference in the chronological age between LI and ASD groups, with children in the ASD group being older than that of the LI group. In other words, the pragmatic language skills displayed by children with ASD resembled that of their younger peers with LI. Therefore, the current finding may indicate a relatively stagnant development of pragmatic language skills in preschoolage children with ASD as compared to children with LI. This result is thus consistent with findings concluded in previous studies which have demonstrated that school-age children with ASD showed a greater degree of pragmatic deficits as compared to those with LI (Geurts \& Embrechts, 2008; Norbury et al., 2004). Importantly, our research suggests that the difference in the degree of pragmatic deficits between children with ASD and LI can be identified even before the school-age years.

It is also worth noting that the deficits in pragmatic language skills across the three subdomains were not statistically significant. Previous research has concluded that the early social communication skills, such as joint attention, gesture use, and quality of communicative overture, are relatively intact in children with LI when compared to children with ASD (Delehanty et al., 2018). The present study, however, did not show advantages by children with $\mathrm{LI}$ in all three subdomains. Therefore, our findings provided evidence that similar profiles of pragmatic language deficits were shared by children with LI and ASD.

With regard to the second research question on the feasibility of using DA to evaluate pragmatic language skills in preschool-age children, the results confirmed that this approach can be adopted to differentiate TD children from children of different clinical groups. Given the nature of pragmatics as a set of context dependent human behaviors, it is believed that the use of OA would provide better insights into the pragmatic language ability than through DA (Adams, 2002). The main argument was that as DA provides a well-controlled environment with discrete tasks and minimal distractions, the accurate picture of pragmatic language deficits would not be revealed. Thus, previous studies commonly adopted observational report measures such as the LUI (O'Neill, 2007) and the CCC-2 (Norbury et al., 2004) or coding systems of naturalistic assessment of interactions (van Balkom \& Verhoeven, 2004) in its investigations. In the present study, we used the Pragmatic Language Skills Subscale from a standardized language assessment instrument. The items in the subscale were constructed with the considerations of contexts and implemented carefully to ensure the participants to have sufficient opportunities to demonstrate their abilities. For instance, the scoring of the presence of eye-contact were based on two separate instances of childinitiated eye contact with the caregivers accompanying the children during the entire testing session; the item on response to name was sequenced at the beginning of the test session to preserve naturalness. The test items successfully identified pragmatic language deficits in both the LI and ASD groups. Therefore, our research provides evidence in support of the use of DA in evaluating pragmatic language skills in preschool-age children with or without neurodevelopmental disorders.

\section{Implications}

This study has both clinical and theoretical implications. As discussed above, many of the previous studies employed methods such as parental checklists and naturalistic assessment of interaction in their investigations of pragmatic language skills in young children. The former approach relies heavily on the informants' comprehension of the items and their abilities to evaluate children's pragmatic language abilities, which are not necessarily overt and easily detected. The latter approach provides information pertaining to the frequency and proportions of individual pragmatic behaviors but remains a time-consuming approach which limits its clinical utility (Norbury, 2014). In contrast, a novelty in our present study was to employ a Pragmatic Language Skills Subscale to conduct assessment directly. The results supported that this approach can be adopted to differentiate TD children from children of different clinical groups, affording both researchers and therapists the efficiency to conduct screening of early pragmatic language skills. Another clinical implication is that despite the traditional view that the social interaction and communication skills are intact in children with LI (Norbury \& Paul, 2015), our findings suggested that they do face substantial challenges in pragmatics when compared to their TD peers. The fact that comparable deficits were found in preschool-age children with LI underscores the importance of the provision of early intervention to this group of children. It is hoped that the increased understanding of the pragmatic language profiles in children with LI will be useful for interventionists to design appropriate treatment programs.

Theoretically, the result also provided empirical evidence to support that children with LI have deficits in the social communication domain which resemble those typically seen in children with ASD (Leyfer et al., 2008; Loucas et al., 
2008; Taylor et al., 2012). The result not only reflected the difficulties in differentiating children with LI and ASD at a young age, but also challenges the conventional diagnostic frameworks that consider LI and ASD as mutually exclusive disorders. Given the overlapping language deficits as indicated in the present study, the potential shared etiology of the two disorders has been examined (Bartlett et al., 2012; Bishop, 2010; Tomblin, 2011). Other accounts including the "phenomimicry" model, which maintains that similar language deficits observed in ASD and LI are of superficial resemblance but not indicative of an etiology overlap at a deeper level have been proposed (Bishop, 2010). To test these different accounts, more pairwise investigations into the different aspects of language phenotypes that display similarity in deficits in these two clinical groups are needed (Williams et al., 2013). In this regard, our findings thus suggested a novel area for researchers to investigate the underpinnings of the two disorders.

\section{Limitations}

Although the current study has several strengths that allowed for new insights into early pragmatic language skills in preschool-age children with or without neurodevelopmental disorders, several limitations are acknowledged. In terms of pragmatic language measures, there are only 11 test items used in the present study with a few representative items for each pragmatic subdomain. Though the selection of test items went through a rigorous psychometric testing process of Rasch analysis, it is possible that the ability to detect and compare pragmatic language deficits across neurodevelopmental disorders groups may have been limited by the small number of test items used. Also, we were not able to compare the results to existing norm referenced tests nor checklists for pragmatics as such instruments are currently not established for Cantonese-speaking preschool-age children. Due to the same reason, our study is limited to using one DA measure instead of employing a range of DAs as in Sturrock et al. (2020). Limitations are also reflected in participants' profiles. The present study included a group of children with ASD consisting mainly of male. An equally balanced gender sample would perhaps have yielded different results. In addition, there was a great variation in the type and severity of symptoms among individuals with ASD. Pragmatic language deficits have been found to be manifested differently in minimally verbal and verbally fluent individuals with ASD (La Valle et al., 2020). We did not include children with ASD who were nonverbal or minimally verbal in this study. Therefore, the sample was not representative of the broader spectrum and thus the generalization of the results should be kept cautious. Furthermore, as the test for the ASD group was conducted online, we were only able to recruit and test families that have electronic access. Finally, the mode of data collection for the ASD group was different from the other groups. Though the testing procedure via video conferencing platform largely followed that of in-person testing, the different conditions such as the familiar home environment for children with ASD may have interfered with the results.

\section{Future Directions}

One critical question for future research is to examine the relationship between structural language abilities and pragmatic language abilities by obtaining the language profiles of preschool-age children. Attempts have been made to tease apart and investigate the associations between the two language domains. A medium to large correlation has been found in TD children (Matthews et al., 2018; Wilson $\&$ Bishop, 2021). There is also a growing evidence supporting that structural language deficits were common and associated with reduced pragmatic competence in children with LI and ASD (Baixauli-Fortea et al., 2019; Greenslade et al., 2019; Levinson et al., 2020; Reindal et al., 2021). Subsequent studies should focus on the interactions between the two domains and compare how the reciprocal relationships are manifested in children with or without neurodevelopmental disorders. Using CFA, it is feasible to evaluate the domain-level differences across groups and variabilities within groups (Wilson \& Bishop, 2020, 2021). An additional benefit of assessing structural language skills is that their language age can also be estimated so that the obstacle of recruiting chronologically age-matched participants with ASD can also be circumvented.

Future work should also include more test items in their DA measures to obtain a more comprehensive picture of the overall and specific pragmatic language skills in different subdomains. By doing so, the effectiveness in capturing the pragmatic deficits can be enhanced. In addition, AndrésRoqueta and Katsos (2020) found that school-age children with ASD were exceptionally challenged by social pragmatics task but performed similarly to those in the LI group in linguistic pragmatics task, suggesting that difficulties with the pragmatic domain were in keeping with the children's structural language. Future studies may include outcome measures that capitalize on the distinction between linguistic and social pragmatics and investigate the potential differences in the pattern and extent of pragmatic language skills in preschool-age children with LI and ASD.

Another important line of research is to explore child and parent characteristics that are associated with developmental outcomes of early pragmatics. Many child characteristics affect language development, including pragmatics (Pace et al., 2017). For instance, previous research 
has shown that various factors such as intellectual quotient and executive functions are generally implicated in pragmatic functions in children (Blain-Brière et al., 2014; Matthews et al., 2018). For parent characteristics, it has been established that parental educational background and socioeconomic status account for variability in prelinguistic skills in children with or without neurodevelopmental disorders (Noble et al., 2015; Olson et al., 2021). Furthermore, there is emerging evidence indicating that parental pragmatic behaviors in terms of the quality and quantity of parent-child interactions predicted children's pragmatic abilities (Di Sante et al., 2020; Schulze \& Saalbach, 2021). Addressing the question of how these characteristics modulate the pragmatic competencies in children using regression analyses could offer methods for optimizing clinician-directed and parent-implemented interventions for children with pragmatic deficits and promote typical pragmatic language development (Parsons et al., 2017; Ramírez et al., 2020).

Finally, the findings from the current study revealed that the pragmatic language skills in preschool-age children with LI and ASD were different from their TD peers. Longitudinal studies tracking the pragmatic functioning in children with or without neurodevelopmental disorders are needed to obtain a comprehensive picture of the developmental trajectories of early pragmatics and to determine the stability of strengths and weaknesses over time, which may facilitate the development of targeted interventions.

Acknowledgements We are grateful to all the children and families who participated in this research study. We would also like to thank all research assistants for assisting in data collection.

Author Contributions KL, IN, and TL contributed to the conceptualization and the overall design of the study. MT provided resources for the conduction of the research. KW and ST performed the research. KW and $\mathrm{WY}$ analyzed the data. KW, KL, and TL edited the paper.

Funding This study was funded by the Health and Medical Research Fund 14152301 from the Food and Health Bureau, Hong Kong Special Administrative Region Government.

\section{Declarations}

Conflict of Interest The authors declare that they have no conflict of interests.

Ethical Approval All procedures have been approved by The Joint Chinese University of Hong Kong-New Territories East Cluster Clinical Research Ethics Committee and are in accordance with the 1964 Helsinki declaration and its later amendments or comparable ethical standards.

Informed Consent Informed consent approved by The Joint Chinese University of Hong Kong-New Territories East Cluster Clinical Research Ethics Committee was obtained from each participant's parents or legal guardians.

\section{References}

Adams, C. (2002). Practitioner review: The assessment of language pragmatics. Journal of Child Psychology and Psychiatry, 43(8), 973-987. https://doi.org/10.1111/1469-7610.00226

American Psychiatric Association. (2013). Diagnostic and statistical manual of mental disorders (5th ed.). American Psychiatric Association. https://doi.org/10.1176/appi.books.9780890425596

Andrés-Roqueta, C., \& Katsos, N. (2020). A distinction between linguistic and social pragmatics helps the precise characterisation of pragmatic challenges in children with autism spectrum disorders and developmental language disorder. Journal of Speech, Language, and Hearing Research, 63(5), 1494-1508. https://doi.org/ 10.1044/2020_JSLHR-19-00263

Baixauli-Fortea, I., Casas, A. M., Berenguer-Forner, C., ColomerDiago, C., \& Roselló-Miranda, B. (2019). Pragmatic competence of children with autism spectrum disorder. Impact of theory of mind, verbal working memory, ADHD symptoms, and structural language. Applied Neuropsychology Child, 8(2), 101-112. https:// doi.org/10.1080/21622965.2017.1392861

Bartlett, C. W., Flax, J. F., Fermano, Z., Hare, A., Hou, L., Petrill, S. A., Buyske, S., \& Brzustowicz, L. M. (2012). Genex gene interaction in shared etiology of autism and specific language impairment. Biological Psychiatry, 72(8), 692-699. https://doi.org/10.1016/j. biopsych.2012.05.019

Bates, E. (1976). Language and context: The acquisition of pragmatics. NY: Academic Press.

Bishop, D. V. M. (2003). The Children's Communication Checklist (CCC-2): CCC-2 manual. Psychological Corporation.

Bishop, D. V. M. (2010). Overlaps between autism and language impairment: Phenomimicry or shared etiology? Behavior Genetics, 40(5), 618-629. https://doi.org/10.1007/s10519-010-9381-x

Blain-Brière, B. P. D., \& candidate, Bouchard, C., \& Bigras, N. . (2014). The role of executive functions in the pragmatic skills of children age 4-5. Frontiers in Psychology. https://doi.org/10. 3389/fpsyg.2014.00240

Bohn, M., Zimmermann, L., Call, J., \& Tomasello, M. (2018). The social-cognitive basis of infants' reference to absent entities. Cognition, 177, 41-48. https://doi.org/10.1016/j.cognition.2018.03. 024

Botting, N., Riches, N., Gaynor, M., \& Morgan, G. (2010). Gesture production and comprehension in children with specific language impairment. British Journal of Developmental Psychology, 28(1), 51-69. https://doi.org/10.1348/026151009X482642

Boucher, J. (2012). Research review: Structural language in autistic spectrum disorder-characteristics and causes. Journal of Child Psychology and Psychiatry, 53(3), 219-233. https://doi.org/10. 1111/j.1469-7610.2011.02508.x

Broekhof, E., Ketelaar, L., Stockmann, L., van Zijp, A., Bos, M. G. N., $\&$ Rieffe, C. (2015). The understanding of intentions, desires and beliefs in young children with autism spectrum disorder. Journal of Autism and Developmental Disorders, 45(7), 2035-2045. https://doi.org/10.1007/s10803-015-2363-3

Brosnan, M., Johnson, H., Grawmeyer, B., Chapman, E., \& Benton, L. (2015). Emotion recognition in animated compared to human stimuli in adolescents with autism spectrum disorder. Journal of Autism and Developmental Disorders, 45(6), 1785-1796. https:// doi.org/10.1007/s10803-014-2338-9

Charman, T., Drew, A., Baird, C., \& Baird, G. (2003). Measuring early language development in preschool children with autism spectrum disorder using the MacArthur Communicative Development Inventory (Infant Form). Journal of Child Language, 30(1), 213-236. https://doi.org/10.1017/S0305000902005482

Choi, B., Shah, P., Rowe, M. L., Nelson, C. A., \& Tager-Flusberg, H. (2020). Gesture development, caregiver responsiveness, and 
language and diagnostic outcomes in infants at high and low risk for autism. Journal of Autism and Developmental Disorders, 50(7), 2556-2572. https://doi.org/10.1007/s10803-019-03980-8

Cook, K. F., Ashton, C. M., Byrne, M. M., Brody, B., Geraci, J., Giesler, R. B., Hanita, M., Souchek, J., \& Wray, N. P. (2001). A psychometric analysis of the measurement level of the rating scale, time trade-off, and standard gamble. Social Science \& Medicine, 53(10), 1275-1285. https://doi.org/10.1016/S0277-9536(00) 00409-3

Cordier, R., Munro, N., Wilkes-Gillan, S., Speyer, R., \& Pearce, W. M. (2014). Reliability and validity of the Pragmatics Observational Measure (POM): A new observational measure of pragmatic language for children. Research in Developmental Disabilities, 35(7), 1588-1598. https://doi.org/10.1016/j.ridd.2014.03.050

Davies, C., Andrés-Roqueta, C., \& Norbury, C. F. (2016). Referring expressions and structural language abilities in children with specific language impairment: A pragmatic tolerance account. Journal of Experimental Child Psychology, 144, 98-113. https://doi. org/10.1016/j.jecp.2015.11.011

Delehanty, A. D., Stronach, S., Guthrie, W., Slate, E., \& Wetherby, A. M. (2018). Verbal and nonverbal outcomes of toddlers with and without autism spectrum disorder, language delay, and global developmental delay. Autism \& Developmental Language Impairments. https://doi.org/10.1177/2396941518764764

Delehanty, A. D., \& Wetherby, A. M. (2021). Rate of communicative gestures and developmental outcomes in toddlers with and without autism spectrum disorder during a home observation. American Journal of Speech-Language Pathology, 30(2), 649-662. https:// doi.org/10.1044/2020_AJSLP-19-00206

Di Sante, M., Sylvestre, A., Bouchard, C., \& Leblond, J. (2020). Parental behaviors associated with the level of pragmatic language ability among 42-month-old neglected children. Child Abuse \& Neglect, 104, 104482. https://doi.org/10.1016/j.chiabu.2020. 104482

Dunn, O. J. (1964). Multiple comparisons using rank sums. Technometrics, 6(3), 241-252. https://doi.org/10.1080/00401706.1964. 10490181

Farmer, M., \& Oliver, A. (2005). Assessment of pragmatic difficulties and socio-emotional adjustment in practice. International Journal of Language \& Communication Disorders, 40(4), 403-429. https://doi.org/10.1080/13682820400027743

Ferrara, M., Camia, M., Cecere, V., Villata, V., Vivenzio, N., Scorza, M., \& Padovani, R. (2020). Language and pragmatics across neurodevelopmental disorders: An investigation using the Italian version of CCC-2. Journal of Autism and Developmental Disorders, 50(4), 1295-1309. https://doi.org/10.1007/s10803-019-04358-6

Geurts, H. M., \& Embrechts, M. (2008). Language profiles in ASD, SLI, and ADHD. Journal of Autism and Developmental Disorders, 38, 1931-1943. https://doi.org/10.1007/s10803-008-0587-1

Gibson, J., Adams, C., Lockton, E., \& Green, J. (2013). Social communication disorder outside autism? A diagnostic classification approach to delineating pragmatic language impairment, high functioning autism and specific language impairment. Journal of Child Psychology and Psychiatry, 54(11), 1186-1197. https://doi. org/10.1111/jcpp.12079

Greenslade, K. J., Utter, E. A., \& Landa, R. J. (2019). Predictors of pragmatic communication in school-age siblings of children with ASD and low-risk controls. Journal of Autism and Developmental Disorders, 49(4), 1352-1365. https://doi.org/10.1007/ s10803-018-3837-x

Hamilton, A. F. (2009). Research review: Goals, intentions and mental states: Challenges for theories of autism. Journal of Child Psychology and Psychiatry, 50(8), 881-892. https://doi.org/10.1111/j. 1469-7610.2009.02098.x

Harms, M. B., Martin, A., \& Wallace, G. L. (2010). Facial emotion recognition in autism spectrum disorders: A review of behavioral and neuroimaging studies. Neuropsychology Review, 20(3), 290-322. https://doi.org/10.1007/s11065-010-9138-6

Hyman, S. L., Levy, S. E., \& Myers, S. M. (2020). Identification, evaluation, and management of children with autism spectrum disorder. Pediatrics, 145(1), e20193447. https://doi.org/10.1542/ peds.2019-3447

Julien, H. M., Finestack, L. H., \& Reichle, J. (2019). Requests for communication repair produced by typically developing preschool-age children. Journal of Speech, Language, and Hearing Research, 62(6), 1823-1838. https://doi.org/10.1044/2019_ JSLHR-L-18-0402

Kasari, C., Gulsrud, A., Freeman, S., Paparella, T., \& Hellemann, G. (2012). Longitudinal follow-up of children with autism receiving targeted interventions on joint attention and play. Journal of the American Academy of Child \& Adolescent Psychiatry, 51(5), 487-495. https://doi.org/10.1016/j.jaac.2012.02.019

Ketelaars, M. P., \& Embrechts, M. T. J. A. (2017). Pragmatic language impairment. In L. Cummings (Ed.), Research in clinical pragmatics (pp. 29-57). Cham: Springer International Publishing.

Kruskal, W. H., \& Wallis, W. A. (1952). Use of ranks in one-criterion variance analysis. Journal of the American Statistical Association, 47(260), 583-621. https://doi.org/10.1080/01621459.1952. 10483441

La Valle, C., Plesa-Skwerer, D., \& Tager-Flusberg, H. (2020). Comparing the pragmatic speech profiles of minimally verbal and verbally fluent individuals with autism spectrum disorder. Journal of Autism and Developmental Disorders, 50(10), 3699-3713. https:// doi.org/10.1007/s10803-020-04421-7

Landa, R. J. (2005). Assessment of social communication skills in preschoolers. Mental Retardation and Developmental Disabilities Research Reviews, 11(3), 247-252. https://doi.org/10.1002/ mrdd.20079

Lawton, K., \& Kasari, C. (2012). Teacher-implemented joint attention intervention: Pilot randomized controlled study for preschoolers with autism. Journal of Consulting and Clinical Psychology, 80(4), 687-693. https://doi.org/10.1037/a0028506

Lee, K. Y. S., Lee, L. W. T., \& Cheung, P. S. P. (1996). Hong Kong Cantonese Receptive Vocabulary Test. The Hong Kong Society for Child Health and Development.

Levinson, S., Eisenhower, A., Bush, H. H., Carter, A. S., \& Blacher, J. (2020). Brief report: Predicting social skills from semantic, syntactic, and pragmatic language among young children with autism spectrum disorder. Journal of Autism and Developmental Disorders, 50(11), 4165-4175. https://doi.org/10.1007/ s10803-020-04445-z

Leyfer, O. T., Tager-Flusberg, H., Dowd, M., Tomblin, J. B., \& Folstein, S. E. (2008). Overlap between autism and specific language impairment: Comparison of Autism Diagnostic Interview and Autism Diagnostic Observation Schedule scores. Autism Research, 1(5), 284-296. https://doi.org/10.1002/aur.43

Longobardi, E., Lonigro, A., Laghi, F., \& O'Neill, D. K. (2017). Pragmatic language development in 18- to 47-month-old Italian children: A study with the language use inventory. First Language, 37(3), 252-266. https://doi.org/10.1177/0142723716689273

Loucas, T., Charman, T., Pickles, A., Simonoff, E., Chandler, S., Meldrum, D., \& Baird, G. (2008). Autistic symptomatology and language ability in autism spectrum disorder and specific language impairment. Journal of Child Psychology and Psychiatry, 49(11), 1184-1192. https://doi.org/10.1111/j.1469-7610.2008.01951.x

Lüke, C., Ritterfeld, U., Grimminger, A., Liszkowski, U., \& Rohlfing, K. J. (2017). Development of pointing gestures in children with typical and delayed language acquisition. Journal of Speech, Language, and Hearing Research, 60(11), 3185-3197. https://doi.org/ 10.1044/2017_JSLHR-L-16-0129

Luyster, R., Lopez, K., \& Lord, C. (2007). Characterizing communicative development in children referred for autism spectrum 
disorders using the MacArthur-Bates Communicative Development Inventory (CDI). Journal of Child Language, 34(3), 623-654. https://doi.org/10.1017/S0305000907008094

Manwaring, S. S., Stevens, A. L., Mowdood, A., \& Lackey, M. (2018). A scoping review of deictic gesture use in toddlers with or at-risk for autism spectrum disorder. Autism \& Developmental Language Impairments, 3, 1-27. https://doi.org/10.1177/ 2396941517751891

Manwaring, S. S., Swineford, L., Mead, D. L., Yeh, C.-C., Zhang, Y., $\&$ Thurm, A. (2019). The gesture-language association over time in toddlers with and without language delays. Autism \& Developmental Language Impairments, 4, 1-15. https://doi.org/10.1177/ 2396941519845545

Martin, G. E., Barstein, J., Hornickel, J., Matherly, S., Durante, G., \& Losh, M. (2017). Signaling of noncomprehension in communication breakdowns in fragile $\mathrm{X}$ syndrome, Down syndrome, and autism spectrum disorder. Journal of Communication Disorders, 65, 22-34. https://doi.org/10.1016/j.jcomdis.2017.01.003

Matthews, D., Biney, H., \& Abbot-Smith, K. (2018). Individual differences in children's pragmatic ability: A review of associations with formal language, social cognition, and executive functions. Language Learning and Development, 14(3), 186-223. https:// doi.org/10.1080/15475441.2018.1455584

Mokkink, L. B., Terwee, C. B., Patrick, D. L., Alonso, J., Stratford, P. W., Knol, D. L., Bouter, L. M., \& de Vet, H. C. W. (2010). The COSMIN study reached international consensus on taxonomy, terminology, and definitions of measurement properties for healthrelated patient-reported outcomes. Journal of Clinical Epidemiology, 63(7), 737-745. https://doi.org/10.1016/j.jclinepi.2010.02. 006

Mundy, P. C. (2016). Autism and joint attention: Development, neuroscience, and clinical fundamentals. Guilford Publications.

Noble, K. G., Engelhardt, L. E., Brito, N. H., Mack, L. J., Nail, E. J., Angal, J., Barr, R., Fifer, W. P., \& Elliott, A. J. (2015). Socioeconomic disparities in neurocognitive development in the first two years of life. Developmental Psychobiology, 57(5), 535-551. https://doi.org/10.1002/dev.21303

Norbury, C. F., \& Paul, R. (2015). Disorders of speech, language, and communication. In A. Thapar, D. S. Pine, J. F. Leckman, S. Scott, M. J. Snowling, \& E. Taylor (Eds.), Rutter's child and adolescent psychiatry (6th ed., pp. 683-701). John Wiley, UK

Norbury, C. F. (2014). Practitioner review: Social (pragmatic) communication disorder conceptualization, evidence and clinical implications. Journal of Child Psychology and Psychiatry, 55(3), 204-216. https://doi.org/10.1111/jcpp.12154

Norbury, C. F., Gemmell, T., \& Paul, R. (2014). Pragmatics abilities in narrative production: A cross-disorder comparison. Journal of Child Language, 41(3), 485-510. https://doi.org/10.1017/S0305 $00091300007 \mathrm{X}$

Norbury, C. F., Nash, M., Baird, G., \& Bishop, D. V. M. (2004). Using a parental checklist to identify diagnostic groups in children with communication impairment: A validation of the Children's Communication Checklist-2. International Journal of Language \& Communication Disorders, 39(3), 345-364. https://doi.org/10. 1080/13682820410001654883

O'Neill, D. K. (2007). The language use inventory for young children: A parent-report measure of pragmatic language development for 18-to 47-month-old children. Journal of Speech, Language, and Hearing Research, 50(1), 214-228. https://doi.org/10.1044/10924388(2007/017)

Olson, L., Kinnear, M., Chen, B., Reynolds, S., Ibarra, C., Wang, T., Linke, A., \& Fishman, I. (2021). Socioeconomic factors account for variability in language skills in preschoolers with autism spectrum disorders. Journal of Developmental and Behavioral Pediatrics, 42(2), 101-108. https://doi.org/10.1097/DBP.00000 00000000870
Osman, D. M., Shohdi, S., \& Aziz, A. A. (2011). Pragmatic difficulties in children with Specific Language Impairment. International Journal of Pediatric Otorhinolaryngology, 75(2), 171-176. https://doi.org/10.1016/j.ijporl.2010.10.028

Pace, A., Luo, R., Hirsh-Pasek, K., \& Golinkoff, R. M. (2017). Identifying pathways between socioeconomic status and language development. Annual Review of Linguistics, 3(1), 285-308. https://doi.org/10.1146/annurev-linguistics-011516-034226

Parsons, L., Cordier, R., Munro, N., Joosten, A., \& Speyer, R. (2017). A systematic review of pragmatic language interventions for children with autism spectrum disorder. PLOS ONE, 12(4), e0172242. https://doi.org/10.1371/journal.pone.0172242

Phelps-Terasaki, D., \& Phelps-Gunn, T. (2007). TOPL-2: Test of Pragmatic Language. Pro-Ed.

Prutting, C., \& Kittchner, D. (1987). A clinical appraisal of the pragmatic aspects of language. Journal of Speech and Hearing Disorders, 52(2), 105-119. https://doi.org/10.1044/jshd.5202.105

Ramírez, N. F., Lytle, S. R., \& Kuhl, P. K. (2020). Parent coaching increases conversational turns and advances infant language development. Proceedings of the National Academy of Sciences, 117(7), 3484-3491.

Rasch, G. (1960). Probabilistic models for some intelligence and attainment tests. Nielson and Lydiche.

Reindal, L., Nærland, T., Weidle, B., Lydersen, S., Andreassen, O. A., \& Sund, A. M. (2021). Structural and pragmatic language impairments in children evaluated for autism spectrum disorder (ASD). Journal of Autism and Developmental Disorders. https://doi.org/10.1007/s10803-020-04853-1

Schertz, H. H., Odom, S. L., Baggett, K. M., \& Sideris, J. H. (2018). Mediating parent learning to promote social communication for toddlers with autism: Effects from a randomized controlled trial. Journal of Autism and Developmental Disorders, 48(3), 853-867. https://doi.org/10.1007/s10803-017-3386-8

Schopler, E., Van Bourgondien, M. E., Wellman, G. J., \& Love, S. R. (2010). CARS-2: Childhood Autism Rating Scale (2nd ed.). Western Psychological Services.

Schulze, C., \& Saalbach, H. (2021). Socio-cognitive engagement (but not socioeconomic status) predicts preschool children's language and pragmatic abilities. Journal of Child Language. https://doi.org/10.1017/S0305000921000295

Song, Y., \& Hakoda, Y. (2018). Selective impairment of basic emotion recognition in people with autism: Discrimination thresholds for recognition of facial expressions of varying intensities. Journal of Autism and Developmental Disorders, 48(6), 1886-1894. https://doi.org/10.1007/s10803-017-3428-2

Stephens, G., \& Matthews, D. (2014). The communicative infant from 0-18 months: The social-cognitive foundations of pragmatic development. In D. Matthews (Ed.), Pragmatic development in first language acquisition (pp. 13-35). Amsterdam: John Benjamins Publishing Company.

Sturrock, A., Marsden, A., Adams, C., \& Freed, J. (2020). Observational and reported measures of language and pragmatics in young people with autism: A comparison of respondent data and gender profiles. Journal of Autism and Developmental Disorders, 50(3), 812-830. https://doi.org/10.1007/ s10803-019-04288-3

Taylor, L. J., Maybery, M. T., \& Whitehouse, A. J. O. (2012). Do children with specific language impairment have a cognitive profile reminiscent of autism? A review of the literature. Journal of Autism and Developmental Disorders, 42(10), 2067 2083. https://doi.org/10.1007/s10803-012-1456-5

Toe, D., Mood, D., Most, T., Walker, E., \& Tucci, S. (2020). The assessment of pragmatic skills in young deaf and hard of hearing children. Pediatrics, 146(Supplement 3), S284-S291. https://doi.org/10.1542/peds.2020-0242H 
Tomasello, M., Carpenter, M., \& Liszkowski, U. (2007). A new look at infant pointing. Child Development, 78(3), 705-722. https://doi. org/10.1111/j.1467-8624.2007.01025.x

Tomblin, B. (2011). Co-morbidity of autism and SLI: Kinds, kin and complexity. International Journal of Language \& Communication Disorders, 46(2), 127-137. https://doi.org/10.1111/j.1460-6984. 2011.00017.x

Tomblin, J. B., Zhang, X., Weiss, A., Catts, H., \& Weismer, S. E. (2004). Developmental language disorders: From phenotypes to etiologies. In M. L. Rice \& S. F. Warren (Eds.), Dimensions of individual differences in communication skills among primary grade children (pp. 53-76). Lawrence Erlbaum Associates Publishers.

van Balkom, H., \& Verhoeven, L. (2004). Pragmatic disability in children with specific language impairments. In L. Verhoeven \& H. van Balkom (Eds.), Classification of developmental language disorders: Theoretical issues and clinical implications (pp. 283305). Lawrence Erlbaum Associates.

Weismer, S. E., Lord, C., \& Esler, A. (2010). Early language patterns of toddlers on the autism spectrum compared to toddlers with developmental delay. Journal of Autism and Developmental Disorders, 40(10), 1259-1273. https://doi.org/10.1007/s10803-010-0983-1

West, K. L., Roemer, E. J., Northrup, J. B., \& Iverson, J. M. (2020). Profiles of early actions and gestures in infants with an older sibling with autism spectrum disorder. Journal of Speech, Language, and Hearing Research, 63(4), 1195-1211. https://doi.org/10.1044/ 2019_JSLHR-19-00013

Williams, D., \& Happé, F. (2010). Representing intentions in self and other: Studies of autism and typical development. Developmental
Science, 13(2), 307-319. https://doi.org/10.1111/j.1467-7687. 2009.00885.x

Williams, D., Payne, H., \& Marshall, C. (2013). Non-word repetition impairment in autism and specific language impairment: Evidence for distinct underlying cognitive causes. Journal of Autism and Developmental Disorders, 43(2), 404-417. https://doi.org/10. 1007/s10803-012-1579-8

Wilson, A. C., \& Bishop, D. V. M. (2019). "If you catch my drift" Ability to infer implied meaning is distinct from vocabulary and grammar skills. Wellcome Open Research, 4, 68.

Wilson, A. C., \& Bishop, D. V. M. (2020). Judging meaning: A domain-level difference between autistic and non-autistic adults. Royal Society Open Science, 7(11), 200845. https://doi.org/10. 1098/rsos.200845

Wilson, A. C., \& Bishop, D. V. M. (2021). A novel online assessment of pragmatic and core language skills: An attempt to tease apart language domains in children. Journal of Child Language. https:// doi.org/10.1017/S0305000920000690

Wray, C., Norbury, C. F., \& Alcock, K. (2016). Gestural abilities of children with specific language impairment. International Journal of Language \& Communication Disorders, 51(2), 174-182. https://doi.org/10.1111/1460-6984.12196

Publisher's Note Springer Nature remains neutral with regard to jurisdictional claims in published maps and institutional affiliations. 